\title{
DISCURSO SOBRE LA ARETÉ
}

\section{SPEECH ON THE EARRING}

(iD) Luis Alberto Bretoneche Gutiérrez ${ }^{1^{*}}$

labguni@gmail.com

${ }^{1}$ Universidad Nacional Mayor de San Marcos, Lima, Perú

*Correspondencia: Luis Alberto Bretoneche Gutiérrez. Email: labguni@gmail.com

Recibido: 10.02.2020 | Aprobado: 09.04.2020

\section{RESUMEN}

En el presente texto se va a trabajar de manera escueta el concepto de areté o virtud sin contenido moral tal como se empleaba en el período helénico y clásico de la historia griega. Se podrá apreciar la manera como los aparentes adjetivos que aparecen calificando los nombres de diferentes personajes históricos o míticos son en realidad el enunciado de la areté que caracteriza a los individuos.

Palabras clave: Virtud, areté, nobleza, excelencia.

\section{ABSTRACT}

In the present text, the concept of areté or virtue without moral content as it was used in the Hellenic and classical period of Greek history is going to be worked on very briefly. It will be possible to appreciate the way in which the apparent adjectives that appear qualifying the names of different historical or mythical personages are in fact the enunciation of the areté that characterizes the individuals.

Keywords: Virtue, areté, nobility, excellence. 


\section{DISCURSO SOBRE LA ARETÉ}

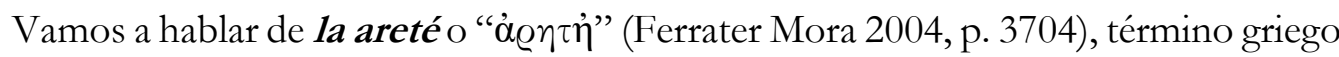
que destaca la excelencia del hombre y que en lengua castellana es relacionada usualmente con el concepto de virtud. Actualmente, cada vez que hablamos de la noción de virtud la relacionamos con un contenido moral, pero esto no era usual en la época helénica y la mayor parte del período clásico de la historia de los pueblos griegos ya que la noción de areté que poseyeron los griegos antiguos era sin contenido moral.

Acerca de lo expuesto, nos cuenta Werner Wilhelm Jaeger (2010) en su libro Paidea: los ideales de la cultura griega, que para entender a los griegos hay que entender la preocupación que este pueblo tenía por educar tanto a sus niños como a sus jóvenes, señala, además, que la enseñanza de la areté es de larga data: "El tema esencial de la historia de la educación griega es más bien el concepto de areté, que se remonta a los tiempos más antiguos" (Jaeger p. 20). Este mismo autor nos dice a continuación que:

El concepto de areté es usado con frecuencia por Homero, así como en los siglos posteriores, en su más amplio sentido, no sólo para designar, la excelencia humana, sino también la superioridad de seres no humanos, como la fuerza de los dioses o el valor y la rapidez de los caballos nobles. El hombre ordinario, en cambio, no tiene areté, y si el esclavo procede acaso de una raza de alta estirpe, le quita Zeus la mitad de su areté y no es ya el mismo que era. La areté es el atributo propio de la nobleza. (Jaeger 2010, p. 21)

Con respecto a lo mencionado por Jaeger y la relación de la areté con la nobleza, por ejemplo, observamos claramente la manera como se narra la areté nobiliaria en la Ilíada de Homero (2006) cuando se menciona el nombre de los principales personajes: el Pelida Aquiles; Aquiles, caro a Zeus, el de los pies ligeros; aqueos, de hermosas grebas; Zeus, el que goza en lanzar rayos, el que lleva la égida; Hera, la de níveos brazos, la de áureo trono; Leto, la de hermosa cabellera; Criseida, la de hermosas mejillas, la hija de Crises; Briseida, la de hermosas mejillas; Héctor, el matador de hombres; teucros, los domadores de caballos; el ingenioso Odiseo; Odiseo, el astuto, igual a Zeus en prudencia; Tetis, la de argénteos pies; Agamenón, el rey de reyes, el rey de hombres; Menelao, valiente en la pelea, caro a Ares; Paris, el de la más hermosa figura, el mujeriego, el seductor; Helena, divina entre las mujeres; etc. ¿Qué se puede observar, leer o escuchar aquí? Simplemente que cuando mencionamos el nombre de algún personaje de la Ilíada, aparece acompañado de un adjetivo calificativo; ese adjetivo no es otra cosa que la areté, la cual aparece señalando la característica principal, la cualidad, la capacidad o la habilidad de un personaje donde se indica la excelencia del hombre al cual se hace referencia y que lo distingue de cualquier otro. Cabe aclarar aquí que cualquiera de estos protagonistas con areté de la obra de Homero puede ser un dios, un héroe (semidiós) o un hombre noble, pero nunca un hombre ordinario o esclavo, pues ellos no la poseían.

Por otro lado, en la Odisea de Homero (2004) también podemos percatarnos de lo mismo, es decir, de la areté sin contenido moral: Atenea, la diosa de los ojos claros, la hija de Zeus; Telémaco, el prudente; Penélope, la prudente, la discreta, la irreprochable, la virtuosa; Eos, la diosa de los dedos rosados, la hija de la mañana; Poseidón, el que circunda las tierras; Artemisa, la que lleva el arco de oro, la casta; Hermes, el mensajero 
de los dioses; Ino, la de los pies hermosos; Calipso, la diosa funesta, la de hermosos cabellos; el divino Ulises; el paciente Ulises y el ingenioso Ulises, entre otros.

Comprender la areté o virtud en los griegos no es fácil. No lo fue antes para los bárbaros y tampoco lo fue en su tiempo para ellos y ahora para nosotros. La palabra bárbaro es un término nada inclusivo que inventaron los helenos para referirse a aquellos que no eran de su lengua, raza, religión y cultura, en general. Acerca de la incomprensión que tenían los bárbaros de la areté de los helenos, podemos percibirlo cuando Herodoto (1989) narra el mensaje de ayuda que los atenienses solicitan a los espartanos por medio de Fidippedes: "Sabed, lacedemonios, que los atenienses os piden que los socorráis, no permitiendo que su ciudad, la más antigua entre las griegas, sea por unos hombres bárbaros reducida a la esclavitud...” (p. 529). ¿Por qué los atenienses tenían tanto miedo a los bárbaros? La respuesta es obvia: no era miedo a aquellos sino el pánico que les producía a ellos la pérdida de la areté o virtud de su ciudad y, por ende, a sus ciudadanos y todo lo que esto implicaba: esclavitud, humillación, ofensa, etcétera.

Cuando los bárbaros trataban de comprender la conducta de aquellos griegos que no se doblegaban ante la superioridad numérica en el campo de batalla y que despreciaban el valor del oro, las riquezas, las caricias de las vestales, el miedo, la sed y el hambre, y combatían sólo por su polis y el honor individual, con sentido del honor militar o caballeresco; el esfuerzo era inconmensurable, pero estéril. Esto podemos percibirlo en el relato que hace Herodoto (1989) cuando Jerjes envía un espía a observar la conducta de los espartanos ad portas del enfrentamiento bélico en el Paso de las Termópilas: "Vio, pues, que unos se entretenían en los ejercicios gimnásticos y que otros se ocupaban en peinar y componer el pelo" (p. 641). La reacción de Jerjes ante la derrota sufrida a manos de los lacedemonios fue de incertidumbre: "cómo era posible que siendo ellos un puñado de gente nada más, se hubiesen de atrever a pelear con su ejército” (Herodoto p. 642). Incluso después de darles una tregua de cuatro días, envió a los medos a enfrentar la desfachatez y falta de juicio de sus enemigos, pero quedó demostrado a ese mismo rey en ese campo de batalla que duró todo un día: "que tenían allí muchos hombres, pero pocos varones esforzados" (Herodoto p. 643). El esfuerzo de aquellos espartanos por defender el honor de ser un pueblo libre sucumbió al final por la traición y la superioridad numérica del ejército de Jerjes. Allí, donde se sacrificaron los seguidores de Leónidas se erigieron después inscripciones como esta: "contra tres millones pelearon solos aquí, en este sitio, cuatro mil peloponesios" (Herodoto p. 650); o aquella que dice: "Habla a los lacedemonios, amigo, y díles que yacemos aquí obedientes a sus mandatos" (Herodoto p. 650). En pocas palabras, los espartanos que murieron en el campo de batalla conservaron su areté a pesar de la derrota sufrida, pero los que se retiraron como Aritodemo, a pesar de hacerlo por un problema de salud: sufría de oftalmía, sufrió el trato humillante de la pérdida de la areté al ser calificado como alguien que no murió en el campo de batalla: «Al enfermo, Aritodemo, se lo llevaron las tropas que se retiraban, y volvió a Esparta, donde no le impusieron un castigo por su conducta, pero le aplicaron el sobrenombre de Tressas, "el que retrocede"» (Wells, 1952, p. 271), aun cuando muriera tiempo después en el campo de batalla, cercano a la ciudad de Platea. 
Con respecto al sentido de la areté como honor a obtener o conservar en otras esferas de la vida social de los griegos, nos dice Alberto Malet (1939) en la Historia griega que:

En honor de ciertos dioses se celebraban grandes fiestas deportivas o juegos, a los que asistía Grecia entera, para seguir sus diferentes lances con verdadera pasión. A pesar del gusto de los griegos por los ejercicios físicos, estos juegos eran simples espectáculos, como las carreras de caballos o los combates gímnicos. Eran fiestas religiosas durante las cuales se suspendían todas las guerras. Se consagraba a los dioses el triunfo de la belleza y de la fuerza humana. (p. 80)

Ellos, los bárbaros, no comprendían como estos griegos competían en los juegos olímpicos, píticos, ístmicos y nemeos solamente por el placer de subir a un podio y recibir una corona de laurel como símbolo de haber obtenido el reconocimiento a sus esfuerzos, es decir, la areté. Al respecto, señala Malet (1939) que:

Los concurrentes se llamaban atletas, y tenían que ejercitarse durante mucho tiempo antes de presentarse en concurso. Si los vencedores recibían por premio en los juegos una palma, o bien una simple corona de olivo o de laurel, y a veces un trípode, en cambio llegaban a ser en sus ciudades verdaderos personajes a quienes se dispensaban los más grandes honores; eran recibidos triunfalmente, les erigían estatuas y, en fin, los poetas cantaban sus hazañas. (p. 81)

Lo mismo ocurría con aquellos que participaban en las olimpiadas con sus obras poéticas, tragedias y comedias. Según Malet (1939): "Las letras y las artes también muestran la unión que existía entre los griegos. En los grandes juegos era frecuentes que se recitaran poemas, se cantara y se expusieran cuadros y estatuas" (p. 81). En otras palabras, no simplemente se destacaban las habilidades corporales o físicas sino también las artísticas.

Sin embargo, la areté o virtud con contenido moral aparecerá después con los aportes de los grandes filósofos del período clásico y helenístico de la historia griega. Sócrates, Platón y Aristóteles van a destacar en ese período, pero este asunto puede ser tema de otro discurso.

En consecuencia con lo expuesto, se puede aseverar que los griegos fueron conocidos -desde el período homérico o helénico hasta gran parte del período clásicopor su vocación, dedicación y participación en todo tipo de eventos, pero no para ganar presentes materiales, regalos ni caricias, tampoco medallas de oro ni de plata, ni siquiera de bronce; ellos iban a competir para ganar sólo una corona de olivo o laurel donde pretendían alcanzar el reconocimiento de los demás al esfuerzo hecho en las actividades que participaban, iban a competir para alcanzar la areté o virtud, a ser reconocidos como los mejores entre los mejores, es decir, los excelentes por el atrevimiento. Esta fue la areté de los tiempos homéricos y que alcanzó hasta los tiempos clásicos donde aparecieron nuevas figuras y le dieron a la areté otros brillos. 


\section{REFERENCIAS BIBLIOGRÁFICAS}

Ferrater Mora, J. (2004). Diccionario filosófico. (3 $3^{a}$ reimpresión revisada, aumentada y actualizada por el profesor Josep-María Terricabras). (Vol. IV). Barcelona: Editorial Ariel, 2004.

Herodoto. (1989). Los nueve libros de historia. Madrid: Edaf.

Homero. (2006). Ilíada. Madrid: Espasa Calpe.

Homero. (2004). Odisea. Lima: Editorial Sol.

Jaeger, W. W. (2010). Paidea: los ideales de la cultura griega. México: FCE.

Malet, A. (1944). Historia griega. Buenos Aires: Librería Hachette.

Wells, H. G. (1952). Esquema de la Historia Universal (Vol. I). Buenos Aires: Ediciones Anaconda.

CITAR COMO:

Bretoneche Gutiérrez, L. A. (2020). Discurso sobre la areté. Puriq, 2(2), 83-88. https://doi.org/10.37073/puriq.2.2.63 